\title{
A PESCA ARTESANAL NA CIDADE VELHA NUM CONTEXTO DE PATRIMONIALIZAÇÃO DO ESPAÇO
}

\section{FISHING CRAFT IN CIDADE VELHA}

IN SPACE PATRIMONIALIZATION CONTEXT

\author{
Maria de Lourdes Silva Gonçalves*
}

\section{Introdução}

Cabo Verde é um país insular com uma extensa Zona Econômica Exclusiva (ZEE) de 789.4 mil km², apesar da dimensão limitada da sua plataforma continental que é de $5.394 \mathrm{~km}^{2}$. Nos últimos anos o país, em cooperação com seus congêneres vizinhos da África e da Europa, vem se esforçando no alargamento da sua fronteira afım de ampliar o seu potencial haliêutico que ronda os 36.000 a 44.000 toneladas/ano (CENSO, 2008).Não obstante a exiguidade dos recursos disponíveis no bojo da ZEE, o mar terri- torial de Cabo Verde possui espécies migratórias comercialmente importantes, como os tunídeos, pequenas espécies pelágicos das quais referencia-se a cavala, o chicharro, o arenque; alguns peixes demersais e lagostas. Espécies que fazem do mar um local especialmente cobiçado, tanto para o desenvolvimento de acordos de exploração como de capturas ilegais. Na sequência da sua cobiça, outrora, século XV, XVI, XVII foi explorada por parte dos corsários europeus e navegadores do aquém e do além mar.

Nas ilhas, particularmente, no meio rural a pesca à semelhança da agricultu-

\footnotetext{
* É Doutora em Desenvolvimento Rural pela Universidade Federal do Rio Grande do Sul - UFRGS (Porto Alegre/RS/Brasil). Membro do Conselho Ciêntífico da Universidade de Cabo Verde - Uni-CV (Praia/ Cabo Verde). É Professora auxiliar e pesquisadora, vinculada à ECAA, com atuação nos Programas de Pós-Graduação em Gestão e Políticas Ambientais; Ciências Sociais; Desenvolvimento e Meio Ambiente e Segurança Pública na Uni-CV. lourdes.goncalves@docente.unicv.edu.cv.
} 
ra tem-se revelado uma atividade de suma importância para o sustento das famílias, sobretudo aquelas residentes em zonas costeiras. Por isso, a sua atividade integra um número significativo de homens e mulheres, chefes de famílias que labutando diariamente no mar, remando de braços firmes e esperançosos buscam, nesta atividade, garantir a sustentabilidade das suas famílias. Realça-se que tal como em outras áreas e atividades no meio rural a questão da divisão sexual do trabalho é proeminente. Embora nos últimos tempos observa-se a paulatina porosidade sexual da fronteira no exercício dessa atividade, tradicionalmente tem-se como estrutural que os homens dedicam à pesca e às mulheres é reservada a sua distribuição e venda.

Hoje, na medida em que os tradicionais eixos de desenvolvimento como as Remessas de Emigrantes e as Ajudas Públicas ao Desenvolvimento (APDs) se encontram em (re)formulação, o setor das pescas vem despertando novas atenções no sentido de ganhar maior relevância econômica, social, na economia do país (peso de pesca no PIB), num contexto em que a sua exploração é confrontada com os desafios de ordem ambiental. 0 setor proporciona rendimentos àqueles que a ele se dedicam, contribui para a redução do desemprego e da pobreza e tem um papel importante na garantia de segurança alimentar das gentes das ilhas.

No entanto, em nome da sustentabilidade da sua exploração a atividade pesqueira, mais concretamente o tipo e os equipamentos utilizados para a pesca bem como o tamanho e a frequência com que determinadas espécies são capturadas, têm despertado grandes preocupações aos decisores políticos, que nos últimos tempos vêm apostando na formação de um corpo de inspetores para o efeito.
Aliás, ante um cenário marcado pela manifesta preocupação coma diversidade biológica, a vulnerabilidade das espécies marinhas, sobretudo nas zonas costeiras tem obrigado os decisores políticos a elaborarem ferramentas jurídicas e a retificarem convenções para gerirem e minimizarem situações em que a lógica da exploração põe em risco o equilíbrio do sistema e comprometer a sustentabilidade intergeracional. No âmbito nacional, destacam-se a criação da Lei de Bases da Política do Ambiente criada em 1993, os Planos Ambientais Intersectoriais da Biodiversidade e das Pescas e os Planos Estratégicos de Gestão dos Recursos da Pesca e de Desenvolvimento da Agricultura que, associados à Convenção sobre a Biodiversidade, ratificado em 1995 pelo Governo buscam garantir uma gestão otimizada da biodiversidade.

Não obstante a existência de medidas legislativas que regulamentam as atividades e objetivam minimizar a pressão sobre esses recursos, o mar de Cabo Verde tem experimentado mudanças outras decorrentes de acordos e contratos de pescas internacionais e regionais que têm resultado no aumento da pressão das capturas das espécies, da extração de areias para construção e de entre outros. Situações que têm refletido na prática pesqueira nas comunidades rurais como as de Cidade Velha, locus da nossa pesquisa, mas também em outras localidades, quais sejam o Porto da Ribeira da Barca, Porto Mosquito, Calheta de São Miguel, Santa Cruz, todos na ilha de Santiago. Locais que agregam famílias caracterizadas por baixos rendimentos e se avolumam as bolsas da pobreza consideráveis existentes no país e que desafiam o Estado a desenvolver estratégias solidárias com os pescadores e suas famílias de forma a 
encontrar alternativas menos impactantes para os recursos protegidos.

É neste contexto que este artigo procura objetivar a análise da dinâmica da pesca artesanal na Cidade Velha, onde se encontra um número considerável de pescadores que dependem desta atividade para a sustentabilidade das suas famílias e que ao mesmo tempo têm lidado no seu quotidiano com uma dupla restrição em termos de desenvolvimento: patrimonialização do espaço, uma configuração jurisdicializada pela UNESCO para a Cidade Velha de Cabo Verde em função da sua historicidade e do seu valor patrimonial e a conservação dos recursos marinhos, no âmbito de assinaturas e retificações de Convenção sobre a Diversidade Biológica na perspectiva da conservação ambiental.

\section{Cidade Velha de Cabo Verde: a patrimo- nialização do espaço e as restrições da ati- vidade pesqueira}

Situada na embocadura conhecida pela Ribeira Grande de Santiago nome do município a que faz parte, Cidade Velha, denominação atribuída em relação à cidade (nova) da Praia, foi edificada no século XVI, enquanto primeira cidade européia construída fora do continente no bojo do colonialismo português e no áureo período em que as navegações marítimas e todas as atividades de exploração europeia, incluindo o tráfico negreiro, passavam por Cabo Verde. Pesquisas sólidas no domíneo da história e da cultura com o foco tanto para Cabo Verde como para as potências expansionistas da época tomam-na como "Berço da Nação e da Cultura Cabo-verdiana” (PEREIRA: 2004). Devido à sua localização geográfica muito cedo se constituiu numa posição geoestratégica dada a sua centralidade no Atlântico Sul. 0 Atlântico que constituiu "um campo estruturado de relações quando os povos das suas várias margens estabeleceram contatos seguros e estáveis, abrindo assim caminhos à formação de redes de interdependência” (CORREIA E SILVA: 1995, p.38). Tendo presente o processamento dessas relações e todo o legado histórico existente sob forma de identidade, de história e de cultura, a UNESCO, em 2009, passados cinco séculos da sua construção, declarou a Cidade como sendo Património da Humanidade.

Apesar de se distar a $15 \mathrm{~km}$ da Praia, cidade capital do país e de se possuir incentivos ao turismo em virtude da sua história ligada a rotas de escravos e de todo o comércio transatlântico que legou sítios e monumentos memoriais, a ruralidade lhe é característica. E há de se destacar que a pesca e a agricultura constituem atividades econômicas de maior peso.

Com o seu entourage, a sua população aumentou de 6.321, em 1980, para 8.324, em 2010 (INE, 2010). Uma evolução demográfica que contrasta com o panorama geral de Cabo Verde cuja população no meio rural diminuiu, passando de 190.892, em 1990, para 187.896, em 2010 (INE, 2010). Dados do Plano Diretório Municipal (PDM) apontam para uma alta densidade populacional na cidade com uma média de 7 a 8 agregados familiares, de gerações diferentes, a partilharem o mesmo teto.

Com a elevação da Cidade Velha a Patrimônio Mundial da Humanidade pela UNESCO, em 2009, como em toda a parte onde ocorre a patrimonialização do espaço, várias restrições de uso e de interação foram introduzidas. Nestes termos a população da Ribeira Grande viu-se contraída às alternativas de uso e da exploração econômica no espaço,pois, a categorização de 
um espaço em patrimônio feito em nome da preservação de um legado memorial implica restringir o âmbito das intervenções humanas, sobretudo àquelas que se consideram lesivas à manutenção do status quo alcançado.

Usos e atividades que outrora fluíam para os habitantes e sobre os quais não havia restrições e eram provedores de rendimentos para as famílias encontram-se hoje limitados. Esta limitação imposta pela via da patrimonialização da Cidade Velha respalda na pressão antrópica sobre o provimento comunitário nos recursos marinhos. Todavia, em Cabo Verde, no geral, o uso dos recursos marinhos, mormente no domínio da pesca, tem sido alvo também de limitações.

Cidade Velha e Ribeira Grande de Santiago no geral vivem neste momento sob dupla restrição: patrimonialização do espaço e limitação do uso e sazonamento de recursos pesqueiros. A este último nível, por exemplo, destaca-se a pouca rentabilidade da pesca artesanal face às concorrências decorrentes da pesca industrial instituídas pelos contratos e acordos internacionais, nomeadamente os acordos celebrados com a União Europeia para a pesca de tunídeos e afıns. Neste último em particular, Cabo Verde renovou, em Dezembro de 2014, o acordo de pesca com a União Europeia com uma vigência de 4 anos, 2014-2018. Ao abrigo do novo acordo, 71 navios da EU, nomeadamente de Portugal, Espanha e França, poderão pescar o atum e espécies afıns nas águas caboverdianas. Em contrapartida, a UE pagará a Cabo Verde uma contribuição financeira de 550.000 euros por ano nos dois primeiros anos de aplicação do protocolo e de 500.000 euros por ano nos últimos dois anos. Desta quantia e segundo acordado, metade desta contribuição anual será reservada para promover uma gestão sustentável das pescas em Cabo Verde, incluindo o reforço das capacidades em matéria de controlo e vigilância, e para apoiar as comunidades piscatórias locais.

Cabo Verde define a pesca artesanal, em contraponto à pesca industrial, como sendo "a arte de pesca mais antiga praticada no país, representando 63\% da captura total da pesca artesanal e 93\% do esforço da pesca artesanal. É efetuada por botes de boca aberta de 3 a $9 \mathrm{~m}$ de comprimento e motor fora de borda" (CABO VERDE, 2007, p.176). Diz ainda o documento que normaliza esta atividade que é

Uma pescaria desenvolvida de forma cau-
telosa, a níveis sustentáveis, em especial no
que respeita aos demersais, visando à ma-
nutenção do emprego nas comunidades de
pescadores artesanais e o abastecimento do
mercado local. São definidas as seguintes
medidas de gestão: - Suspensão da proibição
de captura de exemplares de albacora e patu-
do de menos de 3,2 kg;- Reserva de uma zo-
na exclusiva para as atividades das pescarias
artesanais no interior das 3 milhas náuticas
(CABO VERDE, 2007, p.176).

Desta feita, na "cidade do patrimônio" a concorrência ocorre com efeitos marcantes sobre o quotidiano dos pescadores, peixeiras e todos aqueles que dependem desta atividade para a sua subsistência, na justa medida em que os operadores da Cidade Patrimônio ainda recorrem a técnicas tradicionais para captura. Pois, quando se observa a frota marítima cabo-verdiana para a pesca artesanal deparamos com um ratio reduzido entre o número de famílias e quantidade de botes (Gráfico 1) de "boca aberta" e de pequenas dimensões cujo tamanho oscilam entre os 3,5 a 6,5 metros de comprimentos, com capacidade para trans- 
portar 2 a 4 operadores.A linha, o anzol, a rede e o remo constituem os únicos recursos a bordo utilizados numa pesca artesanal ou de subsistência.

De certa forma, a exiguidade dos equipamentos impactam no tempo despendido para captura, na distância percorrida e na quantidade e qualidade de captura de pescado fazendo com que a sua produção seja de baixa rentabilidade quando se compara com o que as embarcações estrangeiras, industriais e de longo curso conseguem.

Acresce-se ainda que as pequenas embarcações das quais os pescadores do país e da Cidade Velha fazem uso estão sujeitas a medidas de segurança impostas pela regulamentação da pesca artesanal pelo que não podem percorrer mais do que 3 milhas da costa, sob pena de pôr em risco a segurança dos seus operadores.

Gráfico 1 - Distribuição espacial de botes da pesca artesanal

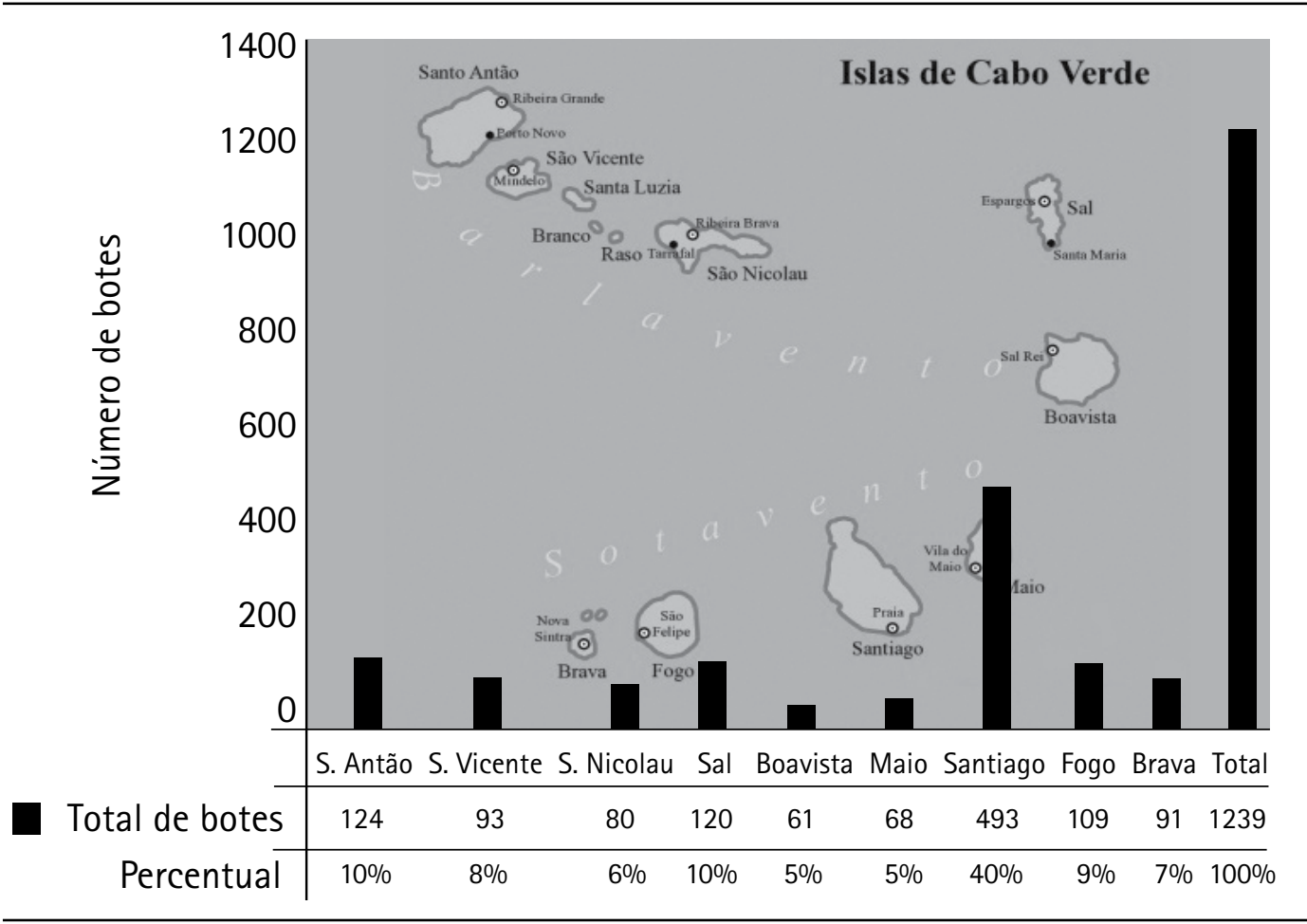

Fonte: INDP, 2012.

Analisando o Gráfico 1, que reporta sobre a distribuição espacial de botes de pesca artesanal nas ilhas de Cabo Verde, com enfoque no bote, instrumento sinequa non para o desenvolvimento da pesca com sustentabilidade para as famílias, observa-se que no total o país possui 1.239 botes para pesca artesanal, num universo populacional de 491.875 habitantes (INE, 2010).
Ainda que nem todo o universo populacional se dedique às pescas, a condição arquipelágica do país e os recursos pesqueiros susceptíveis de serem explorados em Cabo Verde parecem ser sub explorados quando se atenta nos meios disponíveis para o efeito. Isto sem levar em conta a sua precariedade. Do total dos botes registrados existentes, apenas 72\% são motoriza- 
das (INDP, 2012). 0 que significa que $28 \%$ desse meio existente não proporciona aos operadores condições logísticas e de segurança para competirem na captura do pescado dentro dos limites das 3 milhas.

Ainda em termos deste meio, quando se isola para análise apenas a ilha de Santiago, onde se insere a Cidade Velha e as outras comunidades pesqueiras do Município de Ribeira Grande, temos a seguinte situação: dos 493 botes registados na ilha, Ribeira Grande possui apenas 41 , equivalente a $8,3 \%$ para uma população de 8.325 habitantes, o que dá em média 1 bote para 203 famílias. Comparando com outros municípios do país que possuem comunidades pesqueiras como Santa Catarina e Calheta São Miguel, por exemplo, podemos melhor entender a (in)suficiência do ratio bote/população em Ribeira Grande. 0 primeiro, totalizando as duas zonas pesqueiras do Porto de Ribeira da Barca e do Rincão possui um ratio de um bote por 618 habitantes. 0 segundo possui um bote por 1.117 habitantes.

Ao se levar em conta apenas os dados quantitativos do número do ratio bote/ população, o município de Ribeira Grande parece estar-se bem servido em termos desse meio. Porém, a dupla restrição aqui aludida requereria que houvesse um aumento do número de botes, atendendo que as oportunidades de garantir o sustento das famílias encontram-se diminuídas em função daquelas restrições.

Registra-se, entretanto, que os dados acima referenciados são apresentados de forma robusta, tomando os pescadores como unidade de análise fechada. Contudo, quando se dialoga com esta categoria apercebe-se que os pescadores não se ocupam desta atividade em tempo integral. Fazemno acompanhado de outras atividades. $\mathrm{Ou}$ seja, existem, na Cidade Velha, aquilo que Antonio Diegues (1983) denomina de "pescadores-lavradores”, uma categoria analítica que transportada para o campo empírico em análise serve para caracterizar aqueles que combinam a pesca com atividade agrícola, sendo que esta é realizada numa perspectiva de complementaridade. Pois, a atividade agrícola a que se dedicam os pescadores da região é sazonal e ocorre, sobretudo, no período de chuvas, entre os meses de julho a outubro, iniciando pela sementeira até o início da colheita. A pesca, por conseguinte, constitui o meio de produção mais importante dos pescadores e das suas famílias atendendo que é através dela que vem todo o provento econômico do lar, seja para alimentação seja para suportar outras despesas domésticas, com os recursos obtidos da comercialização do pescado.

Assim, se entende que a pesca não é tida pelos pescadores como sua atividade exclusiva, o que possibilita à luz da análise de Mourão (2003) afirmar que entre os pescadores da Cidade Velha não existe uma "ideologia da pesca”. Esta ocorre quando há uma maior racionalidade da atividade pesqueira, da inserção no mercado, da utilização de novas tecnologias de captura, de novas estratégias de conservação, da criação de uma rede de certificação e comercialização.

Os pescadores continuam a pautar por relações informais do trabalho, em que as tarefas são determinadas pelas relações familiares ou de parentesco que integram filhos, pais, irmãos, sobrinhos, genros, compadres e afilhados, baseados em valores como solidariedade e "djuntamón”. Valo-

1. Relação de trabalho que se baseia na reciprocidade, implicando em dar e retribuir. No meio rural caboverdiano a maioria dos trabalhos realizados desencadeia-se com recurso a esse processo. 
res estes que se capitalizados pode consolidar num capital social forte que permitiria a criação de cooperativas locais e empresarialização do setor na Cidade.

Contudo, é preciso levar em consideração que a pesca artesanal largamente realizada nas ilhas de Cabo Verde está sujeita a um conjunto de delimitações que visam preservar a biodiversidade, sobretudo marinha, numa perspectiva de sustentabilidade ambiental. Limitações essas provenientes de acordos e convenções assinados e vertidos em legislações nacionais, traduzidas em algumas medidas de gestão, tais como: o congelamento do número atual de redes de arrasto até que se apure qual o impacto sobre os "stocks" das espécies alvo; a expansão cautelosa do esforço de pesca através do controlo das licenças de pesca;a fixação do tamanho mínimo da dobrada capturada em 17 centímetros de comprimento;a fixação do tamanho mínimo da malha esticada das redes em 30 milímetros; proibição de captura de fêmeas ovadas; reserva da pescaria para os nacionais; fıxação de um período de defeso de 1 de agosto a 30 de setembro para a cavala preta, a vigorar a partir de janeiro de 2008; fixação em 18 centímetros de comprimento furcal o tamanho mínimo da cavala (Acanthocybium solandrila) a ser comercializada, a vigorar a partir de janeiro de 2008; proibição de uso de redes de emalhar; fıxação para as lagostas costeiras de um período de defeso, de 1 de maio a 31 de outubro; fıxação da proibição de captura de exemplares de lagostas costeiras de tamanho igual ou inferior a 9 centímetros de comprimento da carapaça.

Perante tais condicionalismos os pescadores para fazer ecoar as suas vozes, criaram uma associação comunitária denominada de Associação de Pescadores e
Peixeiras de Cidade Velha (APPCV), fundada em 2010 no intuito de congregar e defender seus interesses.

Auscultados no âmbito da realização deste trabalho, os pescadores da Cidade Velha dizem, perante a supra denominada dupla restrição (patrimonialização do espaço e limitações de exploração dos recursos marinhos) por nós articulada, ter apresentado as suas dificuldades ao Estado através do Ministério de Infraestrutura e Transporte Marítimo, órgão que tutela o setor, reivindicando por novas discriminações positivas para a pesca na localidade.

Para tanto, mediante as restrições a que foram sujeitos na cidade e no mar, solicitam novas e modernas embarcações que lhes garantam segurança e maior captura do pescado. Equipamentos como GPS, rádio de comunicação, boias e coletes salva vidas, espaço de restauração naval, arcas congeladoras para conservação dos excedentes, caixas isotérmicas para distribuição e venda informal do pescado e a construção de uma Unidade de Transformação e Agregação do Valor do Pescado (UTAV), constituem meios que concatenados poderão vir a configurar a supra denominada "ideologia da pesca".

Não obstante, segundo os responsáveis do setor, essas reivindicações são na maioria transversais a outras comunidades pesqueiras, em Cabo Verde. No que tange à Cidade Velha, em particular,um tratamento diferenciado que busca alternativas para os moradores se impõe na justa medida em que se encontra limitado o exercício de algumas atividades profissionais geradoras de rendimento. Contudo, essa percepção ainda não ganhou espaço e vez junto de uma das instâncias restritivas - a Curadoria, entidade responsável para gestão e preservação do patrimônio. Nos contatos 
havidos junto desta entidade no sentido de explorar os efeitos sociais restritivos da patrimonialização da Cidade Velha em relação à pesca, não ficou evidente que em relação aos pescadores, peixeiras e os familiares que dependem desta atividade existam algum projeto específico ou ao menos uma preocupação diferenciada para com este grupo.

\section{As encruzilhadas do desenvolvimento (sustentável) no meio rural}

No ponto anterior trouxemos uma análise de uma comunidade rural de uma zona costeira, vítima de duas restrições/ demarcações espaciais que a têm obrigado a (re)configurar o seu modo de vida ou reajustá-lo nos limites das diretrizes impostas. Esta constatação com vértice no local deve ser entendida num contexto mais amplo de desenvolvimento dos Estados Nacionais, sobretudo em África,com parcos recursos que buscam subsidiar o seu processo de desenvolvimento com recursos externos e, na maioria das vezes, obrigados a assumir agendas das instituições financeiras internacionais.

0 processo de desenvolvimento desses Estados, que mobiliza sobremaneira os recursos exógenos para a sua viabilização acaba por submeter a diretrizes externas específicas que chocam e (re)difinem de forma abrupta os modos de vida locais sem a apresentação de alternativas credíveis ao contexto social, econômico e cultural.

Este artigo perfilha um conceito de desenvolvimento que vai na linha daqueles que advogam uma perspectiva de desenvolvimento que tem como seu eixo axial o carácter induzido do conceito. 0 desenvolvimento induzido com o qual operamos aqui de empréstimo, "corresponde às mudanças sociais de inspiração ocidental institucionalizadas nas sociedades atuais" (KNIPPENBERG; SCHUURMAN, 1994, p.102-104; HOLL; MIDGLEY, 1988). Nos termos do exposto, o desenvolvimento heteroenduzido nos países africanos deriva da ideia do progresso e acredita-se ter um triplo impacto nestas sociedades funcionando como: (1) uma divisa geral de orientação; (2) um poderoso instrumento de mobilização e (3) uma idiologia. Esta ideia latente no conceito corrobora um complexo desenvolvimentista que é possível de se encontrar nesses países que respaldam desde o período colonial. A divulgação desse complexo conta com um conjunto de operadores de desenvolvimento - pessoas tidas como altamente qualificadas, para desenvolverem os outros - os atrasados (ESCOBAR apud MILANO, 2013).

Para Najafizadeh e Mennerick (1992) esses operadores são compostos por especialistas dos Governos e das Agências Nacionais e Internacionais que formulam políticas de desenvolvimento; os cientistas sociais que pesquisam e teorizam sobre os países ditos em desenvolvimento; os especialistas de várias disciplinas que idealizam projetos de desenvolvimento e os práticos de desenvolvimento que implementam projetos.

No tocante às restrições do setor pesqueiro e o seu impacto sobre as comunidades, concorreram tanto os desafios da preservação da biodiversidade marinha, uma perspectiva externa, por um lado,como as parcerias de pesca resultantes de acordos multilaterais entre os Estados. Duas influenciações que representam a exogeneidade do processo de desenvolvimento.

Em Cabo Verde, o país, desde a sua origem e formulação pelas elites políticas, demonstrou um grande percurso de dependência 
das agendas e das agências internacionais por via de importação de legislação e de captação de recursos técnicos e financeiros.

As estratégias de importação e de reprodução de instituições e processos de desenvolvimento por parte da elite política são não só produtos de "dinâmicas de orfandade” (BADIE; HERMET, 1993, p.180181) como, paradoxalmente, encontram nestas abrigo de legitimação.Apoiar-se neste argumento é, além do mais, assumir a ideia de que a problemática de importação de modelos institucionais não é ex-nihilo - não surge do nada. Ou seja, quando se pretende compreender por que, ao ser atravessada por determinadas "conjunturas críticas"2, uma elite se empenha em procurar modelos exógenos que melhor lhe auxiliem em promover mudanças, "dinâmicas de orfandade" ${ }^{3}$ aparecem como indutoras das apostas.

Porém, neste contexto de mimetização institucional, surgem fatores outros, não menos importantes, como a circulação das elites, a mediação política, a reprodução do status quo e a configuração mundial daquilo que Negri e Hardt (2004, p.53) denominaram de um biopoder sob a forma de império imbuído de um corpus de moralismo apto a difundir e/ou impor. 0 que tudo somado acaba por coadjuvar e induzir efeitos acumuladores ao processo de importação.

Neste sentido, as políticas de conservação da Biodiversidade, contemporânea da Política de Conservação Ambiental em Cabo Verde, ganharam expressão a partir da Cimeira de Rio92.A realização desse encontro coincidiu com as reformas democráticas introduzidas a partir da institucionalização da democracia em 1991, em que a própria Constituição Democrática do país, de 1992, em seu artigo 7º, alínea "k", consagra como tarefas do Estado proteger a paisagem, a natureza, os recursos naturais e o meio ambiente, bem como o patrimônio histórico-cultural e artístico nacional.

De lá para cá, o Estado de Cabo Verde, vem sendo signatário dos mais diversos acordos em nome da moralidade ambiental e patrimonial. Destes acordos, para o campo em análise, destaca-se a Convenção sobre a Diversidade Biológica assinada em 1994 e ratificada em 1995. Na sequência, a nível nacional, o país foi dotado de um conjunto de ferramentas legais que, na esteira desta Convenção, regulam o setor das pescas tendo em vista a proteção das espécies, mas também a sua abertura ao mercado global. Destaca-se para este último os acordos de pesca com a União Europeia, com a China, com o Senegal etc.

Internamente, para regulamentar o setor das pescas, foi produzido um conjunto de legislação como: Decreto-Lei $n^{-}{ }^{\circ}$ 53/2005 que define os princípios gerais da política de aproveitamento sustentável dos recursos haliêuticos - B.0. n-032 I-a Série de 8 de agosto de 2005, traduzidas nas limitações anteriormente elencadas; a Resolução n-o 3/2005 que aprova o Plano de Gestão dos Recursos da Pesca - B.0. n- 8 I-a Série de 21 de fevereiro de 2005; o De-

2. Ensaia-se aqui uma explicação baseada em criticaljunctures (COLLIER; COLLIER, 1991) para a qual eventos discretos, os quais poderiam exercer isoladamente efeitos apenas residuais, quando combinados e simultâneos seriam capazes de alterar equilíbrios institucionais, criando condições para a mudança.

3. Construto explicativo cunhado nos autores em referência para explicar a desfiliação dos Estados periféricos da América Latina, da África e da Ásia que nos seus processos de desenvolvimento, sobretudo em momentos de transição política, romperam com a tradição em nome de uma modernidade institucional importada. 
creto-Lei n- ${ }^{\circ}$ 9/2002 - define as atribuições da Autoridade Competente para a Inspeção dos Produtos da Pesca - B.0. n-o 7 I Série de 11 de março e o Decreto - Regulamentar n- ${ }^{\circ}$ 10/2005 - define o Regime do Conselho Nacional das Pescas - B.0. n- - $^{-1} 4$ I-a Série $^{-3}$ de 31 de outubro de 2005.

Convém ressaltar que os modelos deregulamentação com forte pendor externo que estrutura um alinhamento do Estado às agendas externas, no meio rural, não se restringe apenas ao setor das pescas. Recorda-se, por exemplo, que ainda no âmbito da conservação ambiental, a instituição das áreas protegidas consubstanciadas em parques naturais em regiões rurais de Cabo Verde (Serra Malagueta, Monte Gordo e Fogo - Chã das Caldeiras) constituem exemplos de como os desígnios da conservação são importados e recaem sobre oethos das regiões rurais.

Se é suposto pensar que a introdução de áreas protegidas enquanto "modernidade” poderá contribuir para a construção de novas pontes para o desenvolvimento dos espaços rurais, uma vez que essas infraestruturas de conservação ambiental abrem oportunidades novas como o turismo ecológico, turismo rural e indústria de artesanato, também não é menos provável que essas portas que se abrem fazem-no em virtude do fechamento de atividades outras, outrora configuradoras das comunidades rurais.

Pois, com as pontes e as portas edificadas,o discurso ambientalista enraizado a partir do Rio 92, com consequências proeminentes sobre o gênero, tem refletido diretamente na vida das mulheres. Estas, com as restrições impostas pelos respetivos parques naturais, foram tocadas nas suas atividades quotidianas por terem sido anulados os seus sustentos familiares, como a limitação e a proibição de determinadas práticas agrícolas, da pecuária e de construção, etc. Ora se para o rural se entende, como diz Bernard Kayser, "um modo particular de utilização do espaço e de vida social" (KAYSER, 1990, p.13), compreendese também que o espaço de vida, não sendo estático, é capaz de reelaborar os insumos recebidos numa ótica tanto de reequilíbrio como de desequilíbrio.

A modernização, em seu sentido amplo, redefine, e por vezes anula, as questões referentes à relação campo/cidade, aos clássicos lugares do agricultor e do pescador na sociedade, à importação social, cultural e política da sociedade local (WANDERLEY, 2009).

Nos parques Naturais de Serra Malagueta e Fogo, pesquisados por mim (GONÇALVES, 2013), as imposições que emanaram da transformação de espaço impeliram as mulheres à conversão de novas atividades acelerando um processo que já vinha a ocorrer e que em alguns casos são também modalidades pouco conciliadoras da praxis conservacionista. Por exemplo, constata-se que na zona do amortecimento do Parque Natural de Serra Malagueta, nas localidades de Fundura e Passo de Vaca, dezenas de mulheres passaram a dedicar-se à extração de inertes, devastando áreas já arborizadas, quebrando rocha e transformando-a em arreia e brita para venda junto a empresas de construção civil (GONÇALVES, 2009).

Esta forma de provisão das famílias vem ganhando espaço por toda a ilha de Santiago. Nas ribeiras, nas ladeiras e no mar, em Porto de Ribeira da Barca, Gouveia, Chã de Tanque, Engenhos, Flamengos, centenas de mulheresacompanhadas de filhas menores, dedicam a prática de extração de inertes e areia e começam já a ser coadjuvadas por uma rede mais extensa de família e parentesco, incluindo homens e jovens escolari- 
zados que, em virtude do mau ano agrícola e desemprego, também integram este labor.

Se em alguns casos a dedicação a esta atividade decorre da depauperação dos espaços rurais, noutros ela ocorre por via das limitações anteriormente elencadas. É neste sentido que este artigo procurou trazerpara colação o caso da Cidade Velha de Santiago cujos contornos vêm paulatinamente se configurar com o setor das pescas.

Assim como tem acontecido, a título de exemplo, com a demarcação das áreas protegidas, os operadores da pesca, em virtude das duas restrições acima debatidas, vêm sendo assistidos com um conjunto de esparsos projetos no sentido de minimizar os impactos daquelas.Neste âmbito, a pesquisa deu conta da existência de vários projetos de correção no setor das pescas visando o empoderamento das comunidades pesqueiras no país. De entre outros, destacam-se:

- Programa Regional de Pesca da África Ocidental - PRAO-CV, financiado pelo Banco Mundial (Global Environment Facility - GEF - e International Development Association - IDA) eimplementado pela Direção Geral dos Recursos Marinhos, orçado em 8.000.000 USD, para o horizonte temporal de quatro anos (2010 - 2014), o seu objetivo foi o de reforçar agestão dos recursos marinhos e valorizar as capturas locais de forma a alcançar o desenvolvimento sustentável e aumentar os benefícios econômicos;

- Projeto de Implementação de uma Rede de Dispositivos de Concentração de Peixes, concebido para um horizonte de dois anos que decorreuentre 2010-2012, financiado pelo Fundo de Transição das Nações Unidas e gerido pela Orga- nização das Nações Unidas para Alimentação e Agricultura (FA0), em concertação com o Instituto Nacional de Desenvolvimento das Pescas e implementado pela Direção Geral dos Recursos Marinhos, orçamentado em 1.149.762 USD, foi concebido para beneficiar 26 comunidades piscatórias nas Ilhas de Santiago, Maio, Fogo, S. Vicentee Santo Antão, incluindo a Instalação de 110 Dispositivos de Concentração de Peixe, oobjetivo era aumentar as capturas artesanaise contribuir para a melhoria da qualidade de vida dos pescadores artesanais e das suas famílias;

- Projeto Operacional da Pesca Artesanal em Cabo Verde - PODPACV, que decorreu de 2010 a 2012, financiado pela Agência Espanhola de Cooperação Internacional para o Desenvolvimentoimplementado pela Direção Geral de Recursos Marinhos, direcionado para comunidades pesqueiras artesanais em Cabo Verde com destaque para atividade pesqueira artesanal e comercialização dos produtos pesqueiros, o projeto tinha como objetivo o fortalecimento do extensionismo pesqueiro e do associativismo das comunidades pesqueiras;

- implementação de um programa de formação marítima;

- melhoramento da comercialização dos produtos de pesca nas comunidades piscatórias;

- melhoramento das capacidades técnicas do Instituto Marítimo Portuário e do INDP em matéria de fiscalização e do conhecimento do esforço 
pesqueiro e captura por unidade de esforço, respetivamente.

Quando se dialoga com os pescadores, dá-se conta que relativamente a assistência por projetos, apesar dos ganhos conseguidos, persistem ainda alguns desafios. Pois, o desenvolvimento por projeto tem trazido grandes desafios ao país tendo em conta o seu horizonte temporal e a limitação dos recursos financeiros a que estão sujeitos. Desta feita, o fim de um projeto, muitas vezes, ocorre sem que o Estado ou a comunidade tenham adquirido condições que permitirlhes-iam seguir o seu fim. É neste sentido que decorrentes da sua implementação no setor das pescas acima elencados fatores como necessidade deseguimento,monitorização e avaliação após a fase de execução, com a retirada do financiador (nacional e internacional) constituem desafios que merecem ser levados em devida conta quando se faz o planeamento de um projeto.

Ademais a forte dependência dos beneficiários do financiador externo em relação à sustentabilidade dos projetos pode contribuir para que efetivamente os projetos não atingem as metas preconizadas.

\section{Considerações Finais}

Nas ilhas de Cabo Verde, o maior constrangimento no que tange à conservação ambiental tem lugar, sobretudo, no meio rural e nas regiões costeiras. Com efeito, a defesa do ambiente em espaços marcados pela privação de bens, quando não acompanhada de alternativas àqueles que vivem umbilicalmente ligados à terra e ao mar cria resistências e os efeitos da sua institucionalização são, se não mínimos, retardados.

Contudo, quando falamos especificamente da questão da preservação da biodi- versidade fica evidente que Cabo Verde, à semelhança de outros países, vive também este cenário de expansão territorial das paisagens marítimas e terrestres de preservação natural com a crescente preocupação com os recursos existentes, mas com dificuldades de uma incorporação de problemas sociais das famílias na sua estratégia.

De todo modo ainda que se entenda que a preservação ambiental é uma questão de obrigação que requer contratualizações estruturais entre as gerações para a sustentabilidade da vida no planeta, não se pode descurar a possibilidade de manutenção do ser humano, ou seja, a sobrevivência de cada indivíduo num dado momento e lugar.

Suposto era que a maioria das políticas que visam restrições seja ao nível da pesca, da patrimonialização, da criação de áreas protegidas, quando implicasse com as comunidades envolventes traduzisse numa conversão de modos de vida ou na criação de políticas públicas de forma a assistir os efeitos econômicos e sociais decorrentes da sua implementação.

Contudo quando se observa as restrições advinientes da preservação das espécies marinhas com impacto direto na vida das populações nas zonas abrangidas, acrescidas de patrimonialização como é o exemplo do caso aqui explorado de Cidade Velha em Cabo Verde verifica-se que as comunidades afetadas encontram-se providas não com políticas públicas, mas em muitos casos com esparsos projetos de assistência sem alternativas estruturantes de sobrevivência. Situações insustentáveis para as famílias e para a sustentabilidade ambiental que se queiram implementar. 


\section{Referências}

BADIE, B.; BIRNBAUM, P. Sociólogie de L'État. Paris: Grasset, 1979.

BADIE, B; HERMET, G. Política Comparada. México: Fundo de Cultura Económica, 1993.

CABO VERDE. Assembleia Nacional. Constituição da República. Praia, 2010.

CABO VERDE. Boletim Oficial - «B. O.» DA REPÚBLICA DE CABO VERDE. p. 176 I. SÉRIE - No 13 - 2 de Abril, 2007.

CABO VERDE. Direção Geral do Ambiente - DGA. $4^{\circ}$ Relatório Sobre o Estado da Biodiversidade em Cabo Verde. Praia, 2009.

CABO VERDE. Direção Geral do Ambiente -DGA. Action Plan for Implementing the Convention on Biological Diversity's Programme of Work on Protected Areas. MAHOT-DGA, Cabo Verde. Praia, 2012.

CABO VERDE. Direção Geral do Ambiente -DGA. Plano de Acção Nacional para o Ambiente (PANA). PANA II - 2002/2014.Praia, 2004.

COLLIER, R.; COLLIER, D. Shaping the political arena: critical junctures, the labor movement and regime dynamics in Latin America.Princeton: Princeton University Press, 1991.

DIEGUES, A.C. Pescadores, camponeses e trabalhadores do mar. São Paulo: Ática, 2003.

ESCOBAR, A. The Making and unmaking of the Third World through Development. In RAHNEMA, Majid; BAWTREE, Victoria (Eds). The PosDevelopment Reader. Londres e Nova Jersia: Zed Books, Dhaka, University Press, LTD, Halifax e Nova Escócia, 2003. p. 85-93.

GONÇALVES, Maria de Lourdes S. Estados Pós Coloniais em África e a Institucionalização de Políticas Ambientais: Derivas e Importação de Políticas em Cabo Verde. 2013.205.f. Tese (Doutorado em Desenvolvimento Rural) - Faculdade de Ciências Económicas. Programa de Pós-Graduação em Desenvolvimento Rural da Universidade Federal do Rio Grande do Sul, Porto Alegre.
GONÇALVES, Maria de Lourdes S.; CARDOSO, C. Mulheres no Meio Rural em Cabo Verde. Painel Académico. Praia: Jornal A Nação, 2009.

HALL, A.; MIDGLEY, J. Introduction. In HALL, A.; MIDGLEY, J. (Eds). Development Policies: Sociological Perspectives. Manchester: Manchester University Press and New York, 1988.p.1-9,

HARDT, M; NEGRI, A. Império. Lisboa: Livros do Brasil, 2004.

INE.Recenseamento Geral da População e Habitação.Praia: INE - Instituto Nacional de Estatística, 2010.

INPD.Relatório de Principais Resultados do Censo Geral da Frota de Pesca Artesanal e Industrial/Semi-Industrial.Praia: Instituto Nacional de Desenvolvimento e Pescas ANO de 2011. Versão Final Julho/12.

KAYSER, B. La renaissance rurale: sociologie des campagnes du monde occidental. Paris: Armand Colin, 1990.

KNIPPENBERG, J.; SCHUURMAN, L. Blinded by Rainbows: Anti-Modernist and Modernist Desconstrctions of Development. In: SCHUURMAN, J. (ED). Current Issues in Development Studies: Global Aspects of Agency and Structure. Saarbrucken: Verlag fur Entwicklungspolitik Breitenbach, 1994. p.90-106.

MILANO, J. Desenvolvimento e Resilência social em África: Dinâmicas Rurais de Cabinda-Angola. Luanda: Mayamba/Imprensa Nacional de Angola - IN, 2013.

MOURÃO, F. A. Os pescadores do litoral sul de São Paulo. São Paulo: Hucitec/NUPAUB/CEP, 2003.

PEREIRA, D. A. A importância Histórica da Cidade Velha (Ilha de Santiago - Cabo Verde). Praia: Ed. Instituto da Biblioteca Nacional e do Livro, 2004.

WANDERLEY, M. N. B. 0 Mundo Rural como espaço de vida. Porto Alegre:Editora da UFRGS, 2009. 
RESUMO

$\mathrm{Na}$ cidade patrimônio de Cabo Verde - $\mathrm{Ci}$ dade Velha a pesca artesanal é a atividade predominante das famílias, realizada pelos grupos de parentesco com recurso a uso de tecnologias simples de captura. Este artigo procura analisar a dinâmica da pesca no contexto da patrimonialização da cidade e compreender as estratégias adotadas pelos pescadores diante às restrições ambientais e patrimoniais visando à continuidade da atividade na cidade.

\section{PALAVRAS-CHAVE}

Pesca artesanal. Patrimonialização. Projetos de Desenvolvimento. Pobreza e Ambiente.

\section{ABSTRACT}

In the city heritage of Cape Verde - Cidade Velha artisanal fishing is the predominant activity of households held by kinship groups using simple capture technologies. This article analyzes the dynamics of fishing in the context of the city's patrimony understand the strategies adopted by fishermen on the environmental and heritage constraints aimed at continuity of activity in the city.

\section{KEYWORDS}

Artisanal fishing. Patrimony. Development Projects. Environment. 